\title{
Surgical Repair of an Asymptomatic Giant Right Coronary Artery Aneurysm
}

\author{
Saleem Jahangeer ${ }^{1}$ Nadeem Anjum ${ }^{1}$ Aonghus O’Donnell ${ }^{1}$ Kishore Doddakula ${ }^{1}$ \\ ${ }^{1}$ Department of Cardiothoracic Surgery, Cork University Hospital, \\ Cork, Ireland \\ Thorac Cardiovasc Surg Rep 2013;2:6-8.

\begin{abstract}
Address for correspondence Saleem Jahangeer, MB, BCh, BAO, BA, MRCS(I), Department of Cardiothoracic Surgery, Cork University Hospital, Wilton Cork, Cork, Ireland (e-mail: salj2008@yahoo.com).
\end{abstract}

\begin{abstract}
Keywords

- cardiovascular surgery

- coronary bypass surgery

- artery/arteries (includes all peripheral arteries)

- shunts

- heart disease

Background Coronary artery aneurysm (CAA) is a rare finding, being mostly diagnosed on angiography or at autopsies. It is defined as being a dilation of the coronary artery that exceeds the diameter of the patient's largest coronary vessel by 1.5 to 2 times.

Case Report We describe the operative correction of a giant right CAA measuring in excess of $10 \mathrm{~cm}$.

Conclusion Management of giant CAAs is not standardized and surgical strategy remains controversial. In our case, the patient has a successful surgical repair with no postoperative shunts on follow-up investigations.
\end{abstract}

\section{Introduction}

Coronary artery aneurysm (CAA) is rare, with a reported incidence of $1.4 \%$ based on coronary angiographies and autopsies. $^{1,2}$ It is defined as being a dilation of the coronary artery that exceeds the diameter of the patient's largest coronary vessel by 1.5 to 2 times. $^{3}$ Atherosclerotic disease represents the major etiology of CAA with other causes including congenital, dissection, infective, postcoronary intervention, and vasculitic lesions.

\section{Case Report}

A 63-year-old woman was referred to our services following the incidental finding of a widened mediastinum on a chest Xray following a recent fall. Her medical history was significant only for hypertension and marked bilateral varicose veins. She was completely asymptomatic of any cardiac problem. She underwent a computed tomography (CT) angiography and a magnetic resonance imaging that showed a large right coronary artery (RCA) aneurysm measuring a maximal diameter of $10.1 \times 7.2 \mathrm{~cm}$, giving off a branch to the right ventricle and then drains in a tortuous fashion to the lateral cardiac vein, and thence, to the coronary sinus. A coronary angiograph performed showed well-preserved left ventricular function, with a normal centimeter of RCA from the ostium, which led into a large aneurysmal dilatation of the RCA. The aneurysm subsequently narrowed into an enlarged RCA before ending as an arteriovenous (AV) fistula directly to the lateral cardiac vein and onto the coronary sinus ( $\mathbf{- F i g . 1} \mathbf{1}$ ).

The patient was electively admitted to our hospital for aneurysm repair. Following induction and median sternotomy, a large aneurismal dilation of the RCA was evident. The coronary sinus was also very tortuous over the anterior surface of the heart. Ascending aortic and bicaval cannulation with tapes and aortic root vent insertion were performed, and the heart stopped with antegrade and retrograde intermittent cold blood cardioplegia. The aneurysm was opened, with a proximal entry point identified superiorly and a patulous exit point identified. The tapes were removed and the right atrium filled but no connections were seen between the aneurysm and the right atrial or ventricular cavities. The exit point of the aneurysm was closed and the entry point was dissected out and then closed over with Prolene suture received

February 10, 2013 accepted after revision

May 15, 2013

published online

July 1,2013
DOI http://dx.doi.org/

10.1055/s-0033-1348947. ISSN 2194-7635. (c) 2013 Georg Thieme Verlag KG
Stuttgart · New York

License terms

$\Theta(1) \Theta \Theta$ 


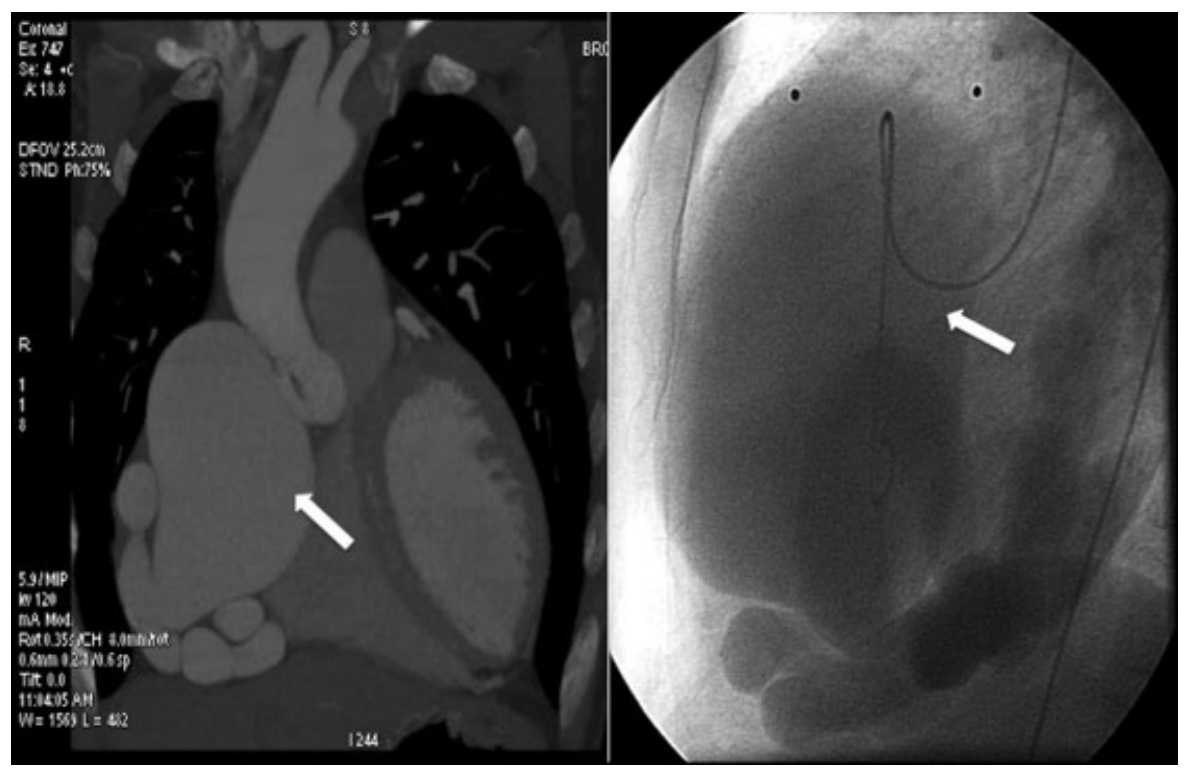

Fig. 1 Coronal view on computed tomography scan showing a massive aneurysm from the right coronary artery (RCA) (white arrow, left). Angiography confirming a large aneurysmal dilation of the RCA (white arrow, right).

(Ethicon, Johnson \& Johnson, Livingston, Scotland, United Kingdom). In view of her significant bilateral varicose veins, the radial artery was harvested and anastomosed in an endto-side fashion to the posterior descending artery (PDA) branch of the RCA. The proximal end of the radial artery was then anastomosed to normal proximal stump of the RCA. As the aneurysm had been controlled and inflow/outflow from the aneurismal segment was also secured, no further measures were taken at that time to address any presence of AV fistula into the coronary sinus (-Figs. 2 and $\mathbf{3}$ ).

Postoperatively, the patient made a very good recovery. An echocardiograph performed showed the RCA repair to be intact. The patient was subsequently discharged from the hospital. Histological examination of the aneurismal sac showed mild intimal thickening together with hyaliniza-

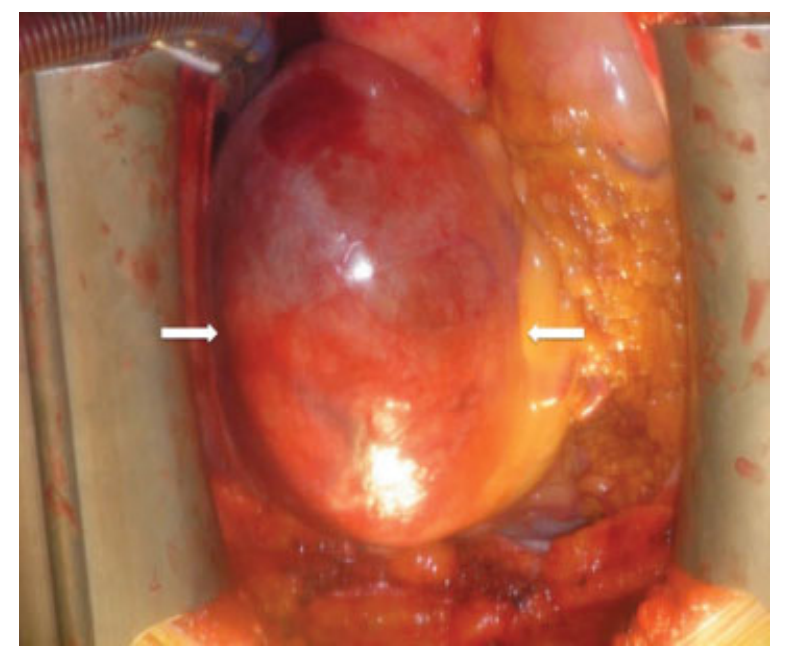

Fig. 2 Intraoperative view following median sternotomy. The aneurysm can be clearly seen (white arrows), occupying almost the whole of the pericardial cavity. tion/fibrosis of the outer part of the wall. There was an associated mild chronic inflammation of the adventitia with collections of lymphocytes and plasma cells but no evidence of an active vasculitis. These features were felt to represent a congenital CAA. A repeat CT angiograph performed 4 months after her surgery showed the radial graft to be patent, and no evidence of any residual shunts.

\section{Discussion}

CAA was first described in 1761 by Morgagni. ${ }^{4,5}$ To date, there exist no control trials of therapy; treatment is based mainly on reported cases in the literature, making the management of CAAs quite challenging.

There have been reported cases where CAA has been managed conservatively on antiplatelet and warfarin therapy, ${ }^{6}$ but most reported cases in the literature involve surgical intervention.

Severity of coexisting coronary artery disease, evidence of embolization, and enlarging aneurysms remain the main indications for surgical intervention. There have been several types of surgical intervention documented.

Harandi et $\mathrm{al}^{7}$ presented an overview of the surgical techniques published so far, concluding that the proper type of operation for this condition is still unclear, but the reported cases with operative therapy have done well, postoperatively, despite a variety of procedures performed.

Although our patient was completely asymptomatic from the viewpoint of her aneurysm, the rapid increase in size and possible complications associated with it, including rupture, infection, and thrombus, were the main reasons in undergoing an elective repair.

At the time of surgery, there was no obvious evidence of any fistula seen. We electively decided not to address this issue, as this would have involved dissecting out the RCA to look for the 


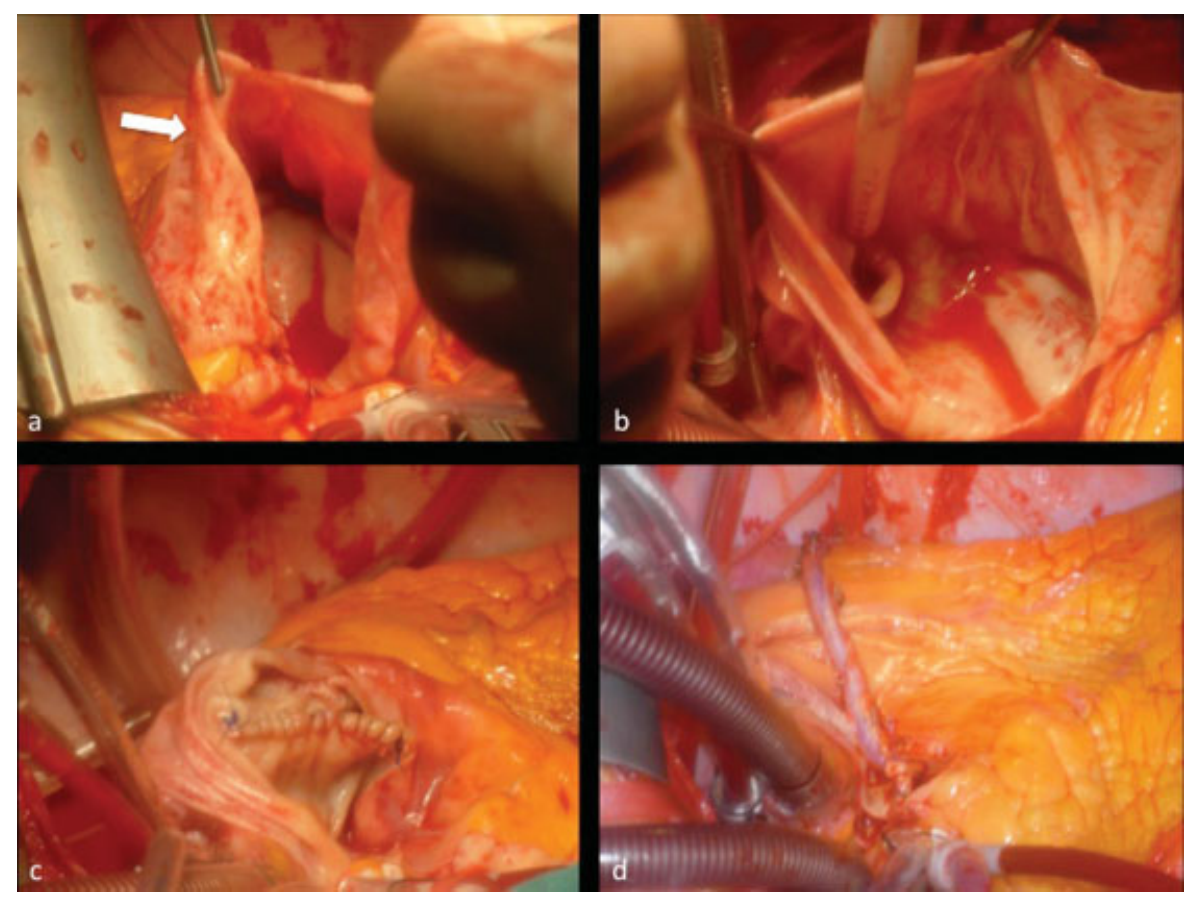

Fig. 3 Surgical repair of the aneurysm. (a) The aneurysmal sac has been opened (white arrow). (b) A patulous entry point (indicated by white suction tip) can be clearly seen. The exit point was identified and closed. (c) The entry point was dissected and sutured closed. (d) The radial artery was anastomosed to the posterior descending artery branch and to the proximal normal right coronary artery, above the oversown stump of the aneurysm.

communication. Doing so would have significantly increased the risk of serious morbidity and mortality for this patient.

\section{References}

1 Grönke S, Diet F, Kilter H, Böhm M, Erdmann E. Charakterisierung der dilatativen Koronaropathie bei Patienten mit und ohne stenosierende koronare Herzkrankheit. Dtsch Med Wochenschr 2005;130(42):2375-2379

2 Daoud AS, Pankin D, Tulgan H, Florentin RA. Aneurysms of the coronary artery. Report of ten cases and review of literature. Am J Cardiol 1963;11:228-237
3 Swaye PS, Fisher LD, Litwin P, et al. Aneurysmal coronary artery disease. Circulation 1983;67(1):134-138

4 Robinson FC. Aneurysms of the coronary arteries. Am Heart J 1985;109(1):129-135

5 Morgagni JB. De sedibus, et causis morborum per anatomen indagatis libri quinque [in Latin]. Vnectus Tom I, Epis 27m Art 28,1761

6 Lima B, Varma SK, Lowe JE. Nonsurgical management of left main coronary artery aneurysms: report of 2 cases and review of the literature. Tex Heart Inst J 2006;33(3):376-379

7 Harandi S, Johnston SB, Wood RE, Roberts WC. Operative therapy of coronary arterial aneurysm. Am J Cardiol 1999;83(8): $1290-1293$ 